\title{
Selection and Performance Evaluation of Local Honeybee (Apis mellifera bandasii) for Stock Improvement in Ethiopia
}

\author{
Taye Negera", Zewudu Ararso, Kibebew Wakjira \\ Oromia Agricultural Research Institute, Holeta Bee Research Center, Holeta, Ethiopia \\ Email address: \\ tayachew2009@gmail.com (T. Negera) \\ ${ }^{*}$ Corresponding author \\ To cite this article: \\ Taye Negera, Zewudu Ararso, Kibebew Wakjira. Selection and Performance Evaluation of Local Honeybee (Apis mellifera bandasii) for \\ Stock Improvement in Ethiopia. Advances in Bioscience and Bioengineering. Vol. 8, No. 3, 2020, pp. $42-49$. \\ doi: $10.11648 /$ j.abb.20200803.11
}

Received: June 24, 2020; Accepted: August 6, 2020; Published: August 13, 2020

\begin{abstract}
Human management and selective breeding are believed to improve many economically important strains of a given honeybee population to benefit the beekeepers. Selective breeding is supposed to be a promising way to estimate value of stock improvement elsewhere, though it is not a common practice in our local honeybees. Thus, to evaluate, select and maintain the best performing stock of local honeybee colonies based on different performance parameters, we obtained 120 honeybee colonies of Apis mellifera bandasii from local beekeepers within traditional hives and transferred into movable frame hive at two apiaries. All the transferred colonies were managed properly to establish themselves and acquire uniform strength. At each of the two sites 50 colonies with similar resources (brood, nectar and pollen) and colony strengths were selected and maintained under continues follow-ups for data collections. The colonies were evaluated for different parameters such as brood development, brood solidness, hygienic behavior and honey yield. The results of the study indicated that honeybee colonies after selection showed significant differences in brood solidness, hygienic behaviors and honey yield compared to honeybee's population before selection. This study revealed a $42 \%$ increment in honey yield only due to selecting and rearing of queens from the best performing lines. Moreover, brood quality (solidness) and hygienic behavior of local honeybee colonies were significantly improved from 86.6 to $94.3 \%$ and $86.0 \%$ to $91.2 \%$ due to selection. From this practical point of view, it is possible to conclude that there is a possibility of improving the production performance of native stock through selection and breeding of maternal lines.
\end{abstract}

Keywords: Apis mellifera bandasii, Honeybee, Brood Rearing, Hygienic Behavior, Stock Improvement

\section{Introduction}

The process of domestication often brings about profound changes in levels of genetic variation in animals and plants. The honeybees, Apis mellifera, has been managed by humans for centuries for both honey and beeswax production and crop pollination. Human management and selective breeding are believed to have improved many economically important strains that benefit beekeepers [14]. Genetic improvement in any organism has the objective of increasing the gene frequencies of the economic importance of loci to be selected in the population. In relation to bees, this means increasing the frequency of the number of colonies that produce above the average generation from which the selection was made [17].
In relation to bees, this means increasing the number of colonies that produce above the average generation from which the selection can be made.[2].

In the majority of selection and breeding programs, economic traits, such as honey productivity and colony strength together with traits desirable for modern beekeeping like gentle temper and low swarming tendency have been of predominant importance [4]. The production of honey and other products is the result of the combine work of the honeybee colony $[6,17]$, and therefore the entire colony becomes a unit of selection, where the assessment of improved queens is carried out by their progeny performance tests $[6,15,17]$. Honey and other bee product production studies allowed to observe considerable variation within a honeybee colonies [2, 5, 17]. For instance, 
it has been reported that selective breeding of queen bees increased honey production by about 30\% [2] and royal jelly production by 10 times [5]. The strong impact of selective breeding on the population is evident due to the significant variability in honeybee colonies. Moreover, queen selection according to honey production has been suggested as an effective tool for improving honey production of a given honeybee population [2]. Furthermore, performance test based selective breeding and mass propagation of selected breeder colonies are well established practice elsewhere [4].

Therefore, the genetic gain was low not only because of the low heritability of traits (influenced by the large environmental variation), but also by low selection differentials observed in the parental generation, as a characteristic genetic gain is equal to the product of their differential selection in the parental generation for its heritability [4]. On the other hand, local beekeepers are currently looking for honeybee colonies with high honey yield and other desirable behavioral traits. For this purpose, selecting and maintaining of a good quality stock of local honeybees through selection is very critical at least to lay foundation for further selective breeding and improvement programs. Therefore, the aim of this preliminary work was to evaluate, select and maintain best performing stock of local honeybee colonies based on stated performance parameters.

\section{Materials and Methods}

\subsection{Study Sites and Colony Treatments}

This study was conducted at two apiaries of Holeta Bee Research Center (Holeta and Muger), Oromia Regional State, Ethiopia from September 2014 to June 2018 for five consecutive years. Honeybee colonies used for the experiment were obtained from local beekeepers found around the two study sites. For this experiment, 120 local $A$. $m$. bandasiicolonies (60 honeybee colonies for each site) in traditional hives were obtained and transferred into movable frame hives in the first month of the first active season (September 2014). All the transferred colonies were managed in uniform manner until they are establishedproperly and acquire uniform strength. At the middle of the first active season, after the colonies were well established and acquired uniform strength, all the colonies were inspected and 100 bee colonies (50 at each site) with similar resources, such as brood, nectar and pollen, and bee population [18] were selected and maintained under continuous follow-ups for data collections.

\subsection{Colony Evaluation Parameters}

\subsubsection{Brood Area}

The area occupied by immature worker honeybees (eggs + larvae + capped brood) in each colony was evaluated every 21 days by overlaying a $5 \times 5 \mathrm{~cm}$ wire grid frame on each side of every brood frame and the area covered with the brood was visually summed [7] (Figure 1).

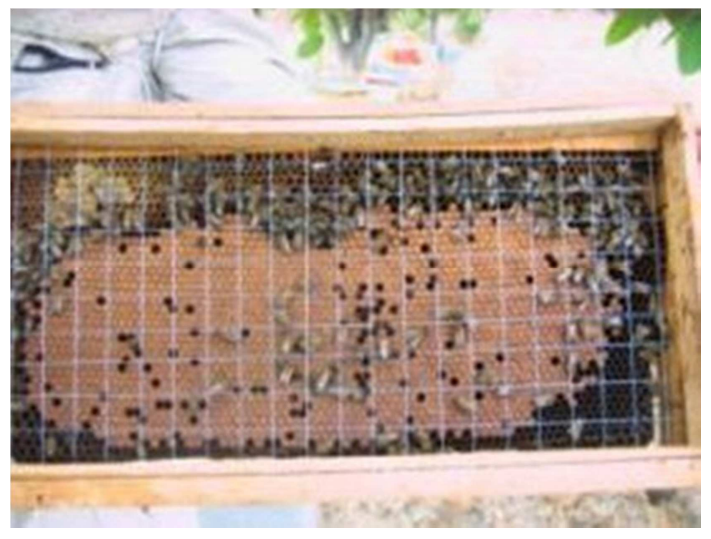

Figure 1. Grid frames placed over brood comb.

\subsubsection{Honey Production}

Harvested honey yield was measured as a difference between weight of honey frames before and after honey extraction, and yield data were recorded for each colony at each apiary site. All honey yield data obtained from each colony were summed up to obtain the total yield from 50 honeybee colonies for each apiary. From the total honey yield, the average honey yield was calculated for the colonies at each apiary at the end of honey flow season. Then, the mean honey yield was compared to the amount of honey yield obtained from each colony and colonies that recorded honey yield above the average were qualified and used for further selection.

\subsubsection{Brood Pattern (Solidness) Test}

Based on the first honey yield results, $40 \%$ of the colonies which were found to perform above the average honey yield were used for the evaluation of brood solidness over four brood rearing seasons (two study years). The degree of worker brood solidity was determined using a piece of cardboard cutting enclosing 10 × 20 worker cells (area enclosing 200 cells) following a method used by Delaplane et al.[7] with little modification (Figure 2). The number of empty cells from these 200 cells was counted and recorded. Based on the total number of empty cells, percentage of viable brood was calculated for each colony under consideration. Colonies with brood solidity $\geq 85 \%$ considered as best performers and selected for the next evaluation for further selection.

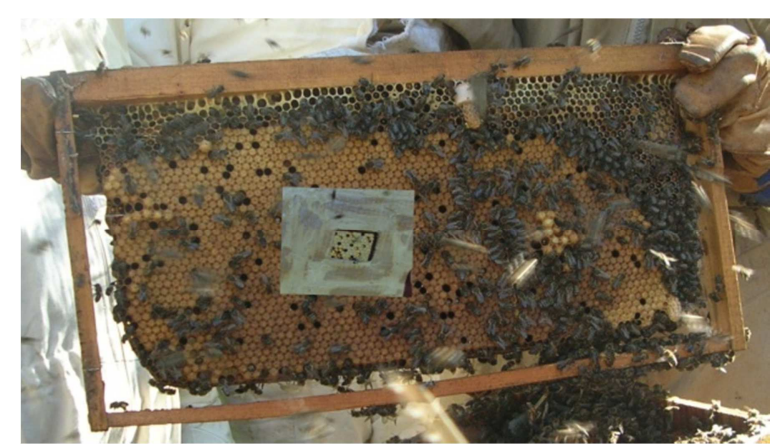

Figure 2. A piece of cardboard with a square equal in size to $10 \times 20$ cells is laid over a patch of brood. Percentage brood solidness is measured directly as (200 - no. empty cells). 


\subsubsection{Hygienic Behavior Test}

For hygienic behavior study of the colonies, pin-killed method was used to evaluate the rate of removal of pin-killed young pupae as described elsewhere [3]. For this purpose, newly sealed brood cells punctured with a fine pin to kill the pupa beneath the capping in each colony. For each pupa only single hole was used to pierce the pupa several times at different angles. The frame with pin-killed brood was marked for easy identification during data collection. After 24 and 48 hours, the number of cells uncapped and cleaned out were

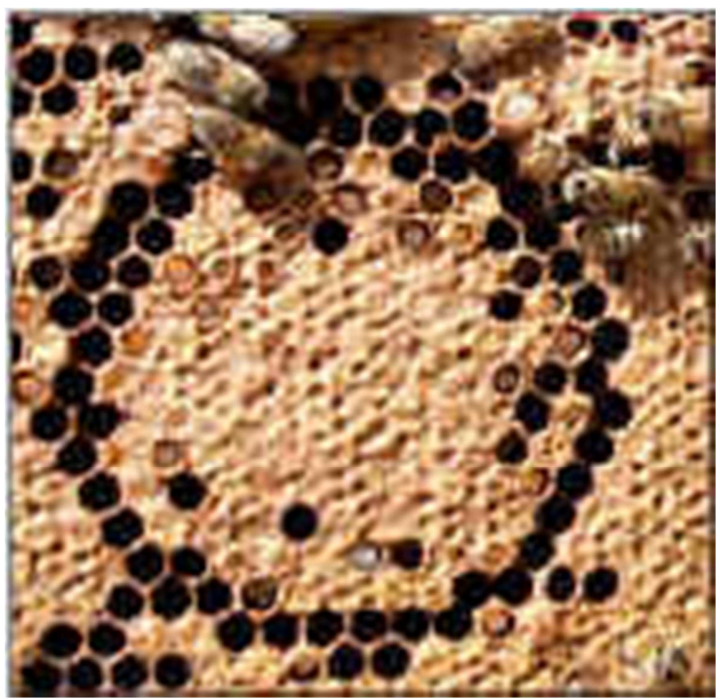

Figure 3. Pin-killed test was used, where 100 cells containing pupae were pierced through the cell capping with an entomological pin size number.

\subsection{Assessment for Further Yield Improvement}

The best performing colonies from each sub-line were used to rear queens to test if there is an improvement in honey yield and other parameters for the second generation colonies. The required virgin queens were reared by using grafting method from parental stock lines selected, those passed through the evaluation criteria for honey production, brood solidity and hygienic behavior. The reared virgin queens were allowed to mate naturally with drones within and around the two areas during active season. This step was repeated every active season. Old queens were replaced by newly reared queens and managed for honey production. Honey yield and brood solidity and hygienic data were collected from colonies headed by the new queens, and compared with the results from the initial colonies.

\section{Statistical Analysis}

All the recorded results were analyzed using descriptive statistics and tested using t-test and general linear (GLM) counted and recorded. After several replications under both environmental conditions, percent removal of dead brood was calculated following a formula previously described [1]. Honeybee colonies that have cleaned at least $90 \%$ of the cells within 48 hours were considered as hygienic colonies and subjected to further evaluation (queen rearing for honey production evaluation). Accordingly, 13 and 12 colonies that displayed high hygienic behavior were selected at Holeta and Muger respectively.

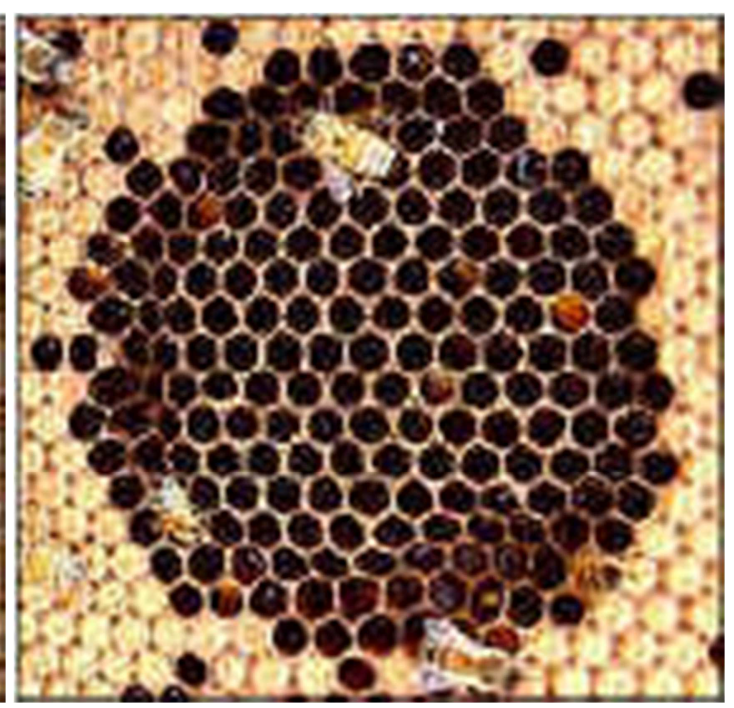

model and presented using tables and graphs.

\section{Results and Discussion}

\subsection{Measurement of Brood Development in Selection Process}

The overall average brood area measured at different times for the honeybee colonies kept at both sites (Holeta and Muger) is presented in Table 1 . Brood rearing activity was not significantly $(p>0.05)$ varied for the colonies at the three time points (before first round culling, before second round culling and after stock-line selection) during the selection process, suggesting that colonies brood rearing tendency could be affected by external factors other than the colony phenotype $[10,17]$. For instance, brood rearing tendency of a colony is significantly affected by environmental conditions [11]. This, may suggest that rate of brood production by honeybee colonies is less important for the preliminary line selection of honeybee colonies.

Table 1. Mean \pm standard error (SE) of brood population and brood solidity of honeybee colonies during selection.

\begin{tabular}{lll}
\hline Category of test colonies & Mean \pm SE of brood area (number of frame) & Mean \pm SE of percent brood solidity \\
\hline Before selection (initial population) & $4.8+0.2^{\mathrm{a}}$ & $86+0.5^{\mathrm{b}}$ \\
After culling colonies performed below average honey yield & $4.7+0.3^{\mathrm{a}}$ & $90.4+0.7^{\mathrm{a}}$ \\
Queens reared from selected colonies & $5.2+0.6^{\mathrm{a}}$ & $91.2+1.4^{\mathrm{a}}$ \\
\hline
\end{tabular}

Means followed by similar letters in the column do not significantly differ $p>0.05$ 


\subsection{Brood Solidness}

Brood solidness is expressed by the percentage of empty worker cells in a brood patch of a given area. In fact, the quality of brood pattern, which is the degree of worker brood solidity, is one of the general measures that indicates the wellbeing of a colony $[12,20]$. In this study, we found that brood solidity in colonies reared from selected lines were significantly $(p<0.05)$ elevated compared that of the initial population (before culling) (Table 1), showing that quality of brood pattern for selected lines is within the acceptable level of empty cells $(<10 \%)$ [7]. This high quality of brood pattern, as indicated by solid patches of capped brood in colonies reared from selected lines of queens, designates line selection elevates brood pattern quality, which in turn, improves brood viability and reduces the risk of colony mortality due to poor brood pattern [12]. This result clearly shows that brood patter can be significantly improved through selective breeding and suggests that brood solidness is an important selection metric to be considered during stock improvement.

\subsection{Hygienic Behavior}

The percent removed dead pupae by the three groups of honeybee colonies (colonies before selection or initial population, colonies after culling those that performed below average in honey yield and colonies reared from selected lines) during the study period are presented in Table 2 . There were significant differences $(\mathrm{p}<0.05)$ in the mean percent of pinkilled pupae removed in 48 hours among the three groups of colonies. The highest dead pupae removal rate per colony was observed in colonies reared from the selected stock (94.3\%) compared to the initial population and colonies maintained based on their first honey yield performances. This result is in line with the finding that colonies of the same subspecies within the same apiary demonstrate different level of hygienic behavior $[8,9,19]$ suggesting that the higher dead pupae removal percent in colonies reared from the selected stock may reflect the substantial effect of selective breeding on improvement of colonies' hygienic behaviour expression. In addition, the observation provides a clue that hygienic behaviour may help the future selective breeding of better performing bee lines.

Table 2. Percentage of pin-killed brood cells from which pupae were completely removed in the three groups of colonies at 48 hours.

\begin{tabular}{ll}
\hline Category of test colonies & Mean \pm SE of percentage pin-killed brood removal \\
\hline Before selection (initial population) & $86.6 \pm 1.0^{\mathrm{b}}$ \\
After culling colonies performed below average honey yield & $90.5 \pm 2.8^{\mathrm{ab}}$ \\
Queens reared from selected colonies & $94.3 \pm 1.4^{\mathrm{a}}$ \\
\hline
\end{tabular}

Means followed by similar letters in the column are not significantly different at $\mathrm{p}>0.05$

\subsection{Honey Yield}

The collected data showed significant $(\mathrm{p}<0.05)$ differences in honey yield among the considered groups of colonies (Table 3 ). Colonies belonging to queens reared from selected colonies tend to produce the highest honey yield $(25.5 \mathrm{~kg})$ compared to the colonies belonging to initial colony population $(18.3 \mathrm{~kg})$. According to these results, the average honey yield of the selected colonies was found to be $41.7 \%$ higher than that produced by initial colonies (before any selection). The main reason for the differences among the groups in the current study could be the continuous production of selected queens from the stock with desirable phenotypic and genetic characteristics [13]. Perfect development and productivity of the colony depends mainly on the quality of its queen [13], as the progeny inherits half of the characteristics from the maternal line. Thus, the current variation in honey yield of selected and non-selected honeybee colonies indicates that heritability of honey production and its gain through selective breeding [8]. It has also been suggested that selection based on this trait (honey production) can yield a good genetic gain, especially if it is used to aid selection [16]. This evidence supports the previous findings which indicated thatthe existing variation in production performance within a population may help to improve the yield through selection.

Table 3. Mean \pm SE of honey yield for honeybee colonies before and after selection.

\begin{tabular}{ll}
\hline Category of test colonies & Mean \pm SE of honey yield (kg/colony/harvest) \\
\hline Before selection (initial population) & $18 \pm 0.4^{\mathrm{c}}$ \\
After culling colonies performed below average honey yield & $21.8 \pm 0.6^{\mathrm{b}}$ \\
Queens reared from selected colonies & $25.5 \pm 1.1^{\mathrm{a}}$ \\
\hline
\end{tabular}

Means followed by similar letters in the column are not significantly different at $p>0.05$

\section{Conclusion and Recommendation}

In this study, the brood quality, hygienic behavior expression and honey yield of the honeybee colonies belonging to selection population was observed to change over time aided with selective breeding. These traits are most important when selection parameters are evaluated before and after stock selection and should be kept in any local honeybee evaluation system for stock improvement. The results show that honey yield could be improved by about $42 \%$ by selecting and using selected stocks based on the traits. From this practical point of view, it is possible to conclude that there is a possibility of improving the 
production performance of native stock through selection and breeding of maternal lines.

Therefore, all the selected and evaluated honeybee colonies have been recommended for the local beekeepers in surrounding area to further promote the colonies stock improvement into the areas where there is a gap in improving honey production.

\section{Acknowledgements}

We greatly acknowledge Oromia Agricultural Research Institute, Holeta Bee Research center for financial assistance. We are very grateful to Mr. Terefe Chimd, Mr. Tesfaye Teshome and Beekeeping and Genetic Improvement Team technical staffs for their respective contributions.

\section{References}

[1] Alemu, T., Legesse, G., and Ararso, Z. (2014). Performance Evaluation of Honeybee (Apis mellifera scutellata) in Guji Zone. Int. J. Innov. Appl. Stud. 9, 1987-1993.

[2] Bar-Cohen, R., Alpern, G., and Bar-Anan, R. (1978). Progeny testing and selecting Italian queens for brood area and honey production. Apid 9, 95-100.

[3] Büchler, R., Andonov, S., Bienefeld, K., Costa, C., Hatjina, F., Kezic, N., et al. (2013). "Standard methods for rearing and selection of Apis mellifera queens," in The COLOSS BEEBOOK, Volume I: standard methods for Apis mellifera research, ed. V. D. J. D. E. P. Neumann (Journal of Apicultural Research 51 (5)), 1-30. doi: 10.3896/IBRA.1.52.1.07.

[4] Buchler, R., Berg, S., and Conte, Y. Le (2010). Review article Breeding for resistance to Varroa destructor in Europe. Apidologie 41, 393-408.

[5] Cao, L.-F., Zheng, H.-Q., Pirk, C. W. W., Hu, F.-L., and Xu, Z.-W. (2016). High Royal Jelly-Producing Honeybees (Apis mellifera ligustica) (Hymenoptera: Apidae) in China. J. Econ. Entomol. 0, 1-5. doi: 10.1093/jee/tow013.

[6] Collins, A. M., Rinderer, T. E., Harbo, J. R., and Brown, M. A. (1984). Heritabilities and correlations for several characters in the honey bee. J. Hered. 75, 135-140. doi: 10.1093/oxfordjournals.jhered.a109888.

[7] Delaplane, K. S., Steen, J. van der, and Guzman-Novoa, E. (2013). "Standard methods for estimating strength parameters of Apis mellifera colonies," in The COLOSS BEEBOOK, Volume I: standard methods for Apis mellifera research, eds. V. Dietemann, J. D. Ellis, and P. Neumann (Journal of

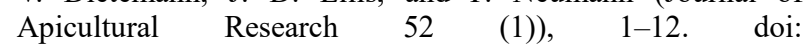
10.3896/IBRA/1.52.1.03.

[8] Garcia, R. C., Tavares, N., Oliveira, E. De, Camargo, S. C., and Pires, B. G. (2013). Honey and propolis production, hygiene and defense behaviors of two generations of Africanized honey bees Honey and propolis production, hygiene and defense behaviors of two generations of Africanized honey bees. Sci. Agric. 70, 74-81.

[9] Güler, A., and Toy, H. (2013). Relationship between dead pupa removal and season and productivity of honey bee (Apis mellifera, Hymenoptera: Apidae) colonies. Turkish J. Vet. Anim. Sci. 37, 462-467. doi: 10.3906/vet-1205-48.

[10] Harbo, J. R. (1986). Effect of Population Size on Brood Production, Worker Survival and Honey Gain in Colonies of Honeybees. 25, 22-29. doi: 10.1080/00218839.1986.11100687.

[11] Hatjina, F., Costa, C., Büchler, R., Uzunov, A., Drazic, M., and Filipi, J. (2014). Population dynamics of European honey bee genotypes under different environmental conditions Population dynamics of European honey bee genotypes under different environmental conditions. doi: 10.3896/IBRA.1.53.2.05.

[12] Lee, K. V., Goblirsch, M., McDermott, E., Tarpy, D. R., and Spivak, M. (2019). Is the Brood Pattern within a Honey Bee Colony a Reliable Indicator of Queen Quality? Insects 10, 12. doi: 10.3390/insects 10010012 .

[13] Ostrovski-tomporoski, K., Faquinello, P., Costa-maia, F. M., Ruvolo-takasusuki, M. C., Santos, R., and Toledo, V. A. De (2016). "Breeding Program Design Principles for Royal Jelly," in Beekeeping and Bee Conservation - Advances in Research, ed. E. D. Chambo (Rijeka, Croatia: InTech), 39-62.

[14] Parker, R., Melathopoulos, A. P., White, R., Pernal, S. F., Guarna, M. M., and Foster, L. J. (2010). Ecological Adaptation of Diverse Honey Bee (Apis mellifera) Populations. PLoS One 5. doi: 10.1371/journal.pone.0011096.

[15] Rinderer, T. E. (1977). Measuring the Heritability of Characters of Honeybees. J. Apic. Res. 16, 95-98. doi: 10.1080/00218839.1977.11099867.

[16] Rinderer, T. E. (1986). Bee Genetics and Breeding. Orlando, FLorida: Academic Press, INC.

[17] Ruvolo-takasusuki, M. C. C., Patricia, A., Casagrande, B., Paula, A., Zago, N., Parpinelli, R. S., et al. (2016). "Improvement and Selection of Honeybees Assisted by Molecular Markers," in Beekeeping and Bee Conservation Advances in Research 1, ed. E. D. Chambo (Rijeka, Croatia: InTech), 63-75.

[18] Taha, E.-K. (2007). Importance of banana Musa sp. (Musaceae) for honeybee Apis mellifera L. (Hymenoptera: Apidae) in Egypt. Bull. Entomol. Soc. Egypt 2, 125-133.

[19] Uzunov, A., Costa, C., Panasiuk, B., Meixner, M., Kryger, P., Hatjina, F., et al. (2014). Swarming, defensive and hygienic behaviour in honey bee colonies of different genetic origin in a pan-European experiment. J. Apic. Res. 53, 248-260. doi: 10.3896/IBRA.1.53.2.06.

[20] Woyke, J. (1981). Effect of Sex Allele Homo-Heterozygosity on Honeybee Colony Populations and on their Honey Production 1. Favourable Development Conditions and Unrestricted Queens. J. Apic. Res. 20, 148-155. doi: 10.1080/00218839.1980.11099997. 